\section{Waist circumference in the prediction of obesity-related adverse pregnancy outcomes}

\author{
Circunferência da cintura na predição de desfechos \\ adversos da gestação relacionados à obesidade
}

\author{
1 Faculdade de Medicina, \\ Universidade Federal \\ do Rio Grande do Sul \\ Porto Alegre, Brazil. \\ Correspondence \\ E. M. D. R. Wendland \\ Faculdade de Medicina \\ Universidade Federal \\ do Rio Grande do Sul. \\ Rua Ramiro Barcelos 2600, \\ sala 414, Porto Alegre, RS \\ 90035-003, Brasil. \\ elianawend@famed.ufrgs.br
}

\begin{abstract}
The aim of this study is to evaluate the diagnostic properties of waist circumference in the prediction of obesity-related gestational outcomes. Pregnant women 20 years or older were consecutively enrolled in six Brazilian State capitals from 1991 to 1995. Weight, height, and waist circumference were measured and an oral glucose tolerance test was performed. Patients were followed through childbirth by chart review. Diagnostic performance for the different outcomes, as measured by area under the receiver operating characteristic (ROC) curve, was estimated through logistic regression. Areas under the ROC curve (95\%CI) for waist circumference were 0.621(0.589-0.652) for gestational diabetes, 0.640 (0.588-0.692) for preeclampsia, and 0.645(0.617-0.673) for macrosomia. These areas were similar to those for BMI $(p>0.05)$. A waist circumference of $82 \mathrm{~cm}$ jointly maximized sensitivity (63\%) and specificity (57\%). Cutoff points of $23 \mathrm{~kg} / \mathrm{m}^{2}$ for pre-pregnancy BMI and $26 \mathrm{~kg} / \mathrm{m}^{2}$ for BMI at enrollment produced similar diagnostic properties. In conclusion, waist circumference predicts obesity-related adverse pregnancy outcomes at least as well as BMI.
\end{abstract}

Obesity; Pregnancy; Anthropometry
Eliana M. D. R. Wendland 1 Bruce Bartholow Duncan 1 Sotero Serrate Mengue 1 Luciana Bertoldi Nucci 1 Maria Inês Schmidt 1

\section{Introduction}

The prevalence of obesity and its related medical consequences are increasing throughout the world, becoming a major problem not only in developed nations but also in many developing countries 1 . Prevalence of obesity during pregnancy has doubled over the past 20 years, and obesity is strongly associated with adverse gestational and perinatal outcomes 2 . For example, anthropometric measurements taken in the antenatal period can predict increased risk of gestational diabetes, preeclampsia, eclampsia, fetal macrosomia, post-term delivery, and cesarean section ${ }^{3}$.

Although obesity is defined as a condition of excessive body fat, it is usually assessed clinically by body mass index (BMI), obtained by dividing weight by height squared 4 . As pregnancy progresses, this index is influenced by gestational weight gain in lean tissues, thus limiting its use in pregnancy ${ }^{5}$. An alternative, the use of pre-pregnancy BMI as an indicator of obesity in pregnancy, may be complicated by the fact that the weight used for this calculation is frequently self-reported, producing inaccuracies.

Abdominal adiposity, measured by waist circumference, is frequently used outside of pregnancy as a risk factor for diabetes and cardiovascular disease 6 . In pregnancy, however, it is seldom used to predict risk, probably because it is believed to be unduly influenced by the increas- 
ing uterine volume. Among the various standardized sites for measuring waist circumference, the minimal waist, being most distant from the growing uterus, is likely to be less influenced.

To contribute information regarding the use of pregnancy measures of obesity in the prediction of adverse gestational outcomes, this study aims to evaluate minimal waist circumference and BMI, assessed using either a reported prepregnancy weight or a weight measured between gestational weeks 20 to 28 , in the prediction of preeclampsia, gestational diabetes, and macrosomia.

\section{Methods}

The Brazilian Study of Gestational Diabetes (EBDG) enrolled 5,564 consecutive pregnant women from May 1991 to August 1995 in health centers belonging to the Unified National Health System in six Brazilian State capitals (Porto Alegre, São Paulo, Rio de Janeiro, Salvador, Fortaleza, and Manaus). Women were eligible if 20 years or older, at weeks 20 through 28 of pregnancy, and with no history of diabetes outside of pregnancy.

Of the 5,564 women enrolled, we excluded 51 patients with twin pregnancy and 262 patients without complete anthropometric measurements, leaving 5,251 for analysis. After additional exclusions related to outcome-specific missing information, we had information available to examine preeclampsia in 4,861 women $(93 \%$ of those included), fetal macrosomia in 3,942 (75\%), gestational diabetes in 4,735 (90\%), and all of these outcomes jointly in 3,649 (69\%).

Information on maternal age, parity, years of formal schooling, and pre-pregnancy weight were obtained through a standardized questionnaire. Weight, height, and waist circumference (minimal abdominal circumference between the lower edge of the ribcage and the iliac crest, or, if the minimal point was not clear, the circumference measured one finger below the lower edge of the ribcage) were obtained in duplicate at enrollment, according to a standardized protocol. A standard oral glucose tolerance test was performed between weeks 24 and 30 of pregnancy. We defined gestational diabetes as blood glucose greater than or equal to $140 \mathrm{mg} / \mathrm{dl}$ two hours after ingestion of $75 \mathrm{~g}$ of anhydrous glucose, in accordance with current WHO criteria 7. Information on hypertensive disorders was obtained from routine prenatal care records and was classified according to the National High Blood Pressure Education Program Working Group 6 . We defined preeclampsia as only new cases of hypertension after week 20 of pregnancy associated with proteinuria or convulsions. Birth weight was obtained by chart review, and when charts were not available through review of birth certificates. Fetal macrosomia was defined as weight above the $90^{\text {th }}$ percentile of birth weight specific to each gestational age in the study ${ }^{8}$.

Sensitivity, specificity, positive and negative predictive values, and the percentage of women classified as positive at each value of waist circumference and BMI were calculated.

We generated ROC (receiver operating characteristic) curves for waist circumference and BMI. The area under the curve, obtained through logistic regression, was used to compare overall diagnostic performance. Contingency tables and areas under the curve, with their respective 95\% confidence intervals, were obtained with SAS (SAS Institute, Cary, USA). Areas were compared with the Hanley \& McNeil method 9 through Analyse-it 1.68 software (Analyse-It Software Ltd., Leeds, UK).

\section{Results}

Table 1 shows characteristics of the 5,564 participants of the EBDG, separately for those having data for all outcomes studied $(\mathrm{N}=3,649)$, and the 1,915 who were either excluded from all analyses $(\mathrm{N}=313)$ or included in some but not all analyses, since they lacked information for a specific outcome $(\mathrm{N}=1,602)$.

For women with complete data, the mean (SD) waist circumference was $81.7(7.7) \mathrm{cm}$, mean gestational BMI was $25.8(3.8) \mathrm{kg} / \mathrm{m}^{2}$, and mean pre-pregnancy BMI was 23.2 (3.8) kg/m². Women without complete data had slightly greater values for all three of these measurements. Given the large sample size, these and several other characteristics presented statistically significant differences between those with and without complete data. However, most of these differences were quite small: women without complete data were slightly older (0.5 years), had slightly more (0.4) pregnancies, somewhat lower educational attainment $(0.6$ grades), and greater $(0.4 \mathrm{~cm})$ uterine height (Table 1).

We identified 354 cases of gestational diabetes $(7.4 \%), 119$ cases of preeclampsia $(2.4 \%)$, and 384 cases of macrosomia (9.7\%). Overall, 663 (18.2\%) of patients presented at least one adverse event. Of these, 604 (16.6\%) presented only one of these adverse outcomes, 56 (1.5\%) presented two associated adverse outcomes, and $03(0.08 \%)$ presented all three study outcomes. The incidence of these adverse outcomes increased with increasing quintiles of the three anthropometric measurements (Table 2). 
Selected characteristics (mean \pm SD) of 5,564 participants in the Brazilian Study of Gestational Diabetes, 1991 to 1995.

\begin{tabular}{|c|c|c|c|}
\hline \multirow[b]{2}{*}{ Variables } & \multicolumn{2}{|c|}{ Study Sample for the Joint Outcome } & \multirow[b]{2}{*}{$\mathbf{p}$} \\
\hline & Analyzed $(n=3649)$ & Excluded $(n=1915)$ & \\
\hline Age (years) & $27.6 \pm 5.3$ & $28.1 \pm 5.8$ & $<0.01$ \\
\hline Height (cm) & $155.5 \pm 6.5$ & $155.6 \pm 6.5$ & 0.63 \\
\hline Educational level (grade) & $8.0 \pm 3.7$ & $7.4 \pm 3.8$ & $<0.01$ \\
\hline Number of previous pregnancies & $1.7 \pm 1.9$ & $2.1 \pm 2.0$ & $<0.01$ \\
\hline Gestational age at interview (days) & $167.27 \pm 21.6$ & $168.02 \pm 19,03$ & 0.22 \\
\hline Uterine height at enrollment (cm) & $22.9 \pm 3.2$ & $23.3 \pm 3.5$ & 0.04 \\
\hline Waist circumference $(\mathrm{cm})$ & $81.7 \pm 7.7$ & $82.9 \pm 8.9$ & $<0.01$ \\
\hline Gestational body mass index $\left(\mathrm{kg} / \mathrm{m}^{2}\right)$ & $25.8 \pm 3.8$ & $26.4 \pm 4.5$ & $<0.01$ \\
\hline Pre-pregnancy body mass index $\left(\mathrm{kg} / \mathrm{m}^{2}\right)$ & $23.2 \pm 3.8$ & $23.7 \pm 4.5$ & $<0.01$ \\
\hline
\end{tabular}

Table 2

Prevalence of gestational diabetes, preeclampsia, and macrosomia according to quintiles of waist circumference, gestational body mass index, and pre-pregnancy body mass index.

\begin{tabular}{|c|c|c|c|c|c|c|c|c|c|c|}
\hline \multirow{3}{*}{ Measure of obesity } & \multicolumn{10}{|c|}{ Quintiles } \\
\hline & \multicolumn{2}{|c|}{1} & \multicolumn{2}{|c|}{2} & \multicolumn{2}{|c|}{3} & \multicolumn{2}{|c|}{4} & \multicolumn{2}{|c|}{5} \\
\hline & $\mathbf{N}$ & $\%$ & $\mathbf{N}$ & $\%$ & $\mathbf{N}$ & $\%$ & $\mathbf{N}$ & $\%$ & $\mathbf{N}$ & $\%$ \\
\hline \multicolumn{11}{|l|}{ Waist circumference * } \\
\hline Gestational diabetes mellitus & 50 & 5.3 & 45 & 4.9 & 52 & 5.5 & 75 & 7.9 & 132 & 13.5 \\
\hline Preeclampsia & 15 & 1.5 & 15 & 1.5 & 25 & 2.5 & 19 & 2.0 & 45 & 5.2 \\
\hline Macrosomia & 37 & 4.7 & 46 & 6.1 & 70 & 9.0 & 91 & 11.4 & 140 & 17.1 \\
\hline \multicolumn{11}{|l|}{ Gestational body mass index ** } \\
\hline Gestational diabetes mellitus & 36 & 3.9 & 54 & 5.7 & 54 & 5.6 & 74 & 8.1 & 136 & 13.9 \\
\hline Preeclampsia & 8 & 0.8 & 25 & 2.4 & 20 & 2.0 & 20 & 2.2 & 46 & 5.3 \\
\hline Macrosomia & 34 & 4.6 & 54 & 6.8 & 71 & 8.8 & 95 & 12.4 & 130 & 15.6 \\
\hline \multicolumn{11}{|l|}{ Pre-pregnancy body mass index ${ }^{\star \star \star}$} \\
\hline Gestational diabetes mellitus & 45 & 4.7 & 52 & 5.6 & 66 & 7.34 & 68 & 6.8 & 123 & 13.0 \\
\hline Preeclampsia & 14 & 1.4 & 20 & 2.0 & 18 & 1.9 & 27 & 2.7 & 40 & 4.7 \\
\hline Macrosomia & 43 & 5.6 & 64 & 8.4 & 75 & 9.8 & 90 & 10.7 & 112 & 13.9 \\
\hline
\end{tabular}

* Waist quintile cutoff points: $\geq 75,79,83,88,122 \mathrm{~cm}$;

** Gestational body mass index quintile cutoff points: $\geq 21,25,26,29$, and $50 \mathrm{~kg} / \mathrm{m}^{2}$;

$\star \star \star$ Pre-pregnancy body mass index quintile cutoff points: $\geq 20,22,24,26$, and $53 \mathrm{~kg} / \mathrm{m}^{2}$;

Differences in the frequencies of all outcomes across quintiles were statistically significant $(p<0.05)$ for all

anthropometric measurements.

Table 3 and Figure 1 summarize the areas under the ROC curves for various anthropometric indices as predictors of gestational outcomes for patients 20 to 27 weeks of gestation. Values closest to the upper left shoulder of each ROC curve indicate maximal combined sensitivity and specificity. For the combined endpoint of any adverse outcome, the difference between areas under the ROC curves for waist circumference and gestational BMI was 0.001, waist circumference and pre-pregnancy BMI 0.036, and pre-pregnancy and gestational BMI 0.036. All areas were significantly different from the reference diagonal, but none was statistically significantly superior to the others $(p>0.05)$ for any of the outcomes studied.

Cutoff points that identify the highest number of subjects with and without the obesity-related outcome varied from 82 to $83 \mathrm{~cm}$ for waist circumference, from 26 to $27 \mathrm{~kg} / \mathrm{m}^{2}$ for gestational BMI, and from 23 to $24 \mathrm{~kg} / \mathrm{m}^{2}$ for pre-pregnancy BMI (Table 4). When the occurrence of any 
Comparison of area under the receiver operating characteristic $(\mathrm{ROC})$ curves for anthropometric measures in detecting obesity-related outcomes in pregnant women aged 20 to 48 years, Brazil.

\begin{tabular}{|c|c|c|c|c|c|c|}
\hline \multirow{4}{*}{$\begin{array}{l}\text { Outcome } \\
\text { Gestational diabetes }\end{array}$} & \multicolumn{6}{|c|}{ Area under the ROC curve and $95 \% \mathrm{Cl}$} \\
\hline & \multirow{2}{*}{\multicolumn{2}{|c|}{$\begin{array}{c}\text { Waist } \\
\text { circumference }\end{array}$}} & \multirow{2}{*}{\multicolumn{2}{|c|}{$\begin{array}{l}\text { Gestational body } \\
\text { mass index }\end{array}$}} & \multirow{2}{*}{\multicolumn{2}{|c|}{$\begin{array}{l}\text { Pre-pregnancy } \\
\text { body mass index }\end{array}$}} \\
\hline & & & & & & \\
\hline & 0.621 & $(0.589-0.652)$ & 0.635 & $(0.604-0.666)$ & 0.615 & $(0.584-0.645)$ \\
\hline Preeclampsia & 0.640 & $(0.588-0.692)$ & 0.655 & $(0.604-0.706)$ & 0.629 & $(0.575-0.682)$ \\
\hline Macrosomia & 0.645 & $(0.617-0.673)$ & 0.632 & $(0.604-0.661)$ & 0.588 & $(0.558-0.617)$ \\
\hline At least one adverse outcome & 0.633 & $(0.610-0.657)$ & 0.634 & $(0.610-0.657)$ & 0.597 & $(0.573-0.621)$ \\
\hline
\end{tabular}

Figure 1

Receiver operating characteristic curve of waist circumference (thin dashed line), gestational (thick solid line) and pre-pregnancy (thick dashed line) body mass index (BMI) in identifying subjects with at least one adverse gestational outcome in the Brazilian Study of Gestational Diabetes: 1991 to 1995 . The joint value of sensitivity and specificity was maximal between 82 and $83 \mathrm{~cm}$ for waist circumference, 25 and $26 \mathrm{~kg} / \mathrm{m}^{2}$ for gestational BMI (GBMI), and 23 and $24 \mathrm{~kg} / \mathrm{m}^{2}$ for pre-pregnancy BMI (PBMI), as shown in the graph.

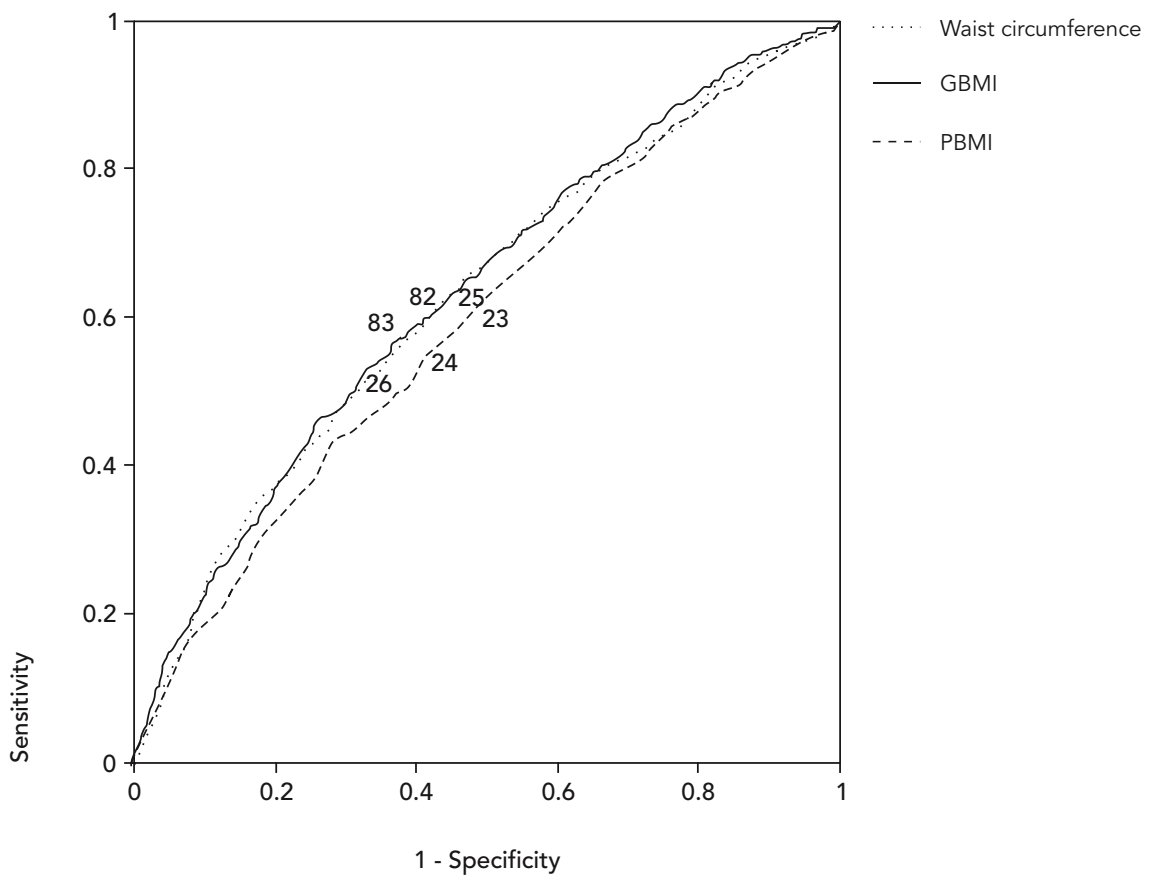


Diagnostic properties (\%) of different cutoff points for waist circumference and gestational and pre-pregnancy body mass index (BMI) in detecting obesity-related outcomes, Brazilian Study of Gestational Diabetes (EBDG), 1991 to 1995.

\begin{tabular}{|c|c|c|c|c|c|c|c|c|c|c|c|c|c|}
\hline \multirow{3}{*}{$\begin{array}{r}\text { Cutoff } \\
\text { Point }\end{array}$} & \multirow[b]{3}{*}{ Test positivity (\%) \# } & \multicolumn{3}{|c|}{ Gestational diabetes } & \multicolumn{3}{|c|}{ Preeclampsia } & \multicolumn{3}{|c|}{ Macrosomia } & \multirow{2}{*}{\multicolumn{3}{|c|}{$\begin{array}{c}\text { Any adverse } \\
\text { gestational outcome }\end{array}$}} \\
\hline & & & & & & & & & & & & & \\
\hline & & $\mathrm{Se}^{*}$ & $\mathrm{Sp}$ ** & PPV *** & $\mathrm{Se}$ & Sp & PPV & $\mathrm{Se}$ & Sp & PPV & $\mathrm{Se}$ & Sp & PPV \\
\hline \multicolumn{14}{|c|}{ Waist circumference $(\mathrm{cm})$} \\
\hline 81 & $50-52$ & 68 & 49 & 10 & 69 & 51 & 3 & 71 & 50 & 15 & 68 & 52 & 26 \\
\hline 82 & $45-47$ & 63 & 55 & 10 & 61 & 57 & 3 & 66 & 55 & 16 & 63 & 57 & 26 \\
\hline 83 & $40-42$ & 59 & 59 & 11 & 55 & 62 & 4 & 62 & 60 & 16 & 58 & 62 & 27 \\
\hline 84 & $35-37$ & 55 & 64 & 11 & 52 & 66 & 4 & 56 & 64 & 17 & 53 & 68 & 28 \\
\hline 85 & $31-33$ & 50 & 68 & 11 & 49 & 70 & 4 & 51 & 69 & 15 & 49 & 71 & 29 \\
\hline \multicolumn{14}{|c|}{ Gestational BMI (kg/m²) } \\
\hline 25 & 56 & 73 & 46 & 10 & 69 & 47 & 3 & 71 & 45 & 12 & 70 & 47 & 24 \\
\hline 26 & $43-44$ & 62 & 57 & 10 & 59 & 59 & 4 & 63 & 57 & 14 & 60 & 59 & 26 \\
\hline 27 & $33-34$ & 54 & 67 & 11 & 50 & 69 & 4 & 52 & 67 & 15 & 50 & 69 & 28 \\
\hline 28 & $25-27$ & 46 & 74 & 13 & 44 & 76 & 4 & 44 & 74 & 15 & 42 & 76 & 30 \\
\hline \multicolumn{14}{|c|}{ Pre-pregnancy BMI $\left(\mathrm{kg} / \mathrm{m}^{2}\right)$} \\
\hline 22 & 58 & 71 & 43 & 9 & 70 & 44 & 3 & 70 & 42 & 12 & 69 & 43 & 23 \\
\hline 23 & $46-47$ & 61 & 54 & 10 & 62 & 56 & 3 & 58 & 53 & 12 & 59 & 55 & 24 \\
\hline 24 & $35-37$ & 52 & 64 & 11 & 51 & 67 & 4 & 49 & 64 & 13 & 48 & 65 & 25 \\
\hline 25 & 28 & 46 & 73 & 12 & 41 & 75 & 4 & 38 & 73 & 13 & 39 & 75 & 27 \\
\hline
\end{tabular}

* Se = sensitivity;

$\star \star S p=$ specificity;

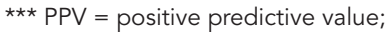

\# Range of test positivity (fraction of sample having a value for the obesity index in question greater than or equal to the specified cutoff point) across the outcomes.

of the three adverse conditions was considered the outcome of interest, no additional gain in diagnostic prediction was found. The prediction of at least one adverse outcome with maximal combined specificity and sensitivity is obtained with a waist circumference of $82 \mathrm{~cm}$ (sensitivity $=63$ and specificity $=57$ ), a gestational BMI of $26 \mathrm{~kg} / \mathrm{m}^{2}$ (sensitivity $=60$ and specificity $=59$ ), and a pre-pregnancy BMI of $23 \mathrm{~kg} / \mathrm{m}^{2}$ (sensitivity $=59$ and specificity $=55$ ) (Figure 1 ).

Secondary analysis (data not shown) with waist circumference, including only women with uterine fundal height less than $27 \mathrm{~cm}$, produced similar results. For example, the area under the ROC curve evaluating diagnostic properties for the detection of at least one adverse outcome in this secondary analysis was 0.646 (vs. 0.641 for the whole sample, $\mathrm{p}>0.05$ ).

\section{Discussion}

The present study provides diagnostic properties for various obesity indices that are potentially useful in the prediction of adverse pregnancy outcomes. We found that waist circumference, measured between 20 and 28 weeks of gestation, is as good a predictor of these outcomes as BMI based on weight taken at the same period, or on a reported pre-pregnancy weight, as judged by similar areas under the ROC curves (Figure 1). A waist circumference cutoff point of $82 \mathrm{~cm}$ has equivalent diagnostic properties (when sensitivity and specificity are jointly maximized) to a BMI of $26 \mathrm{~kg} / \mathrm{m}^{2}$ taken at the same period, and to a pre-pregnancy BMI of $23 \mathrm{~kg} / \mathrm{m}^{2}$, in the identification of obesity-related adverse gestational outcomes.

Maternal obesity, usually defined on the basis of pre-pregnancy BMI, is associated with a higher incidence of many pregnancy complications. The risk of developing hypertensive disorder and preeclampsia has been shown to increase according to levels of pre-pregnancy BMI 10, gestational BMI taken in the first prenatal visit 5 , or pre-pregnancy body weight 11 . A systematic review 12 evaluating preeclampsia and pre-pregnancy BMI showed that the risk doubles 
for each $5-7 \mathrm{~kg} / \mathrm{m}^{2}$ increase in BMI. Obesity, evaluated as BMI during or before pregnancy, is also associated with an increased risk of gestational diabetes $5,11,13$. Obesity is also considered a risk factor for macrosomia 2,5,13, when assessed by BMI.

Of note, most studies that used BMI based on pregnancy weight usually took the weight obtained during the first prenatal visit, utilizing BMI cutoff points derived from non-pregnant populations. Moreover, most studies assessing cutoff points for BMI were based on techniques to compare risks rather than to compare diagnostic properties.

According to our results, gestational BMI had similar predictive capacity to pre-pregnancy BMI, as judged by similar areas under the ROC curves. However, while simultaneously optimizing sensitivity and specificity in the prediction of obesity-related outcomes, we found an optimal cutoff point of $23 \mathrm{~kg} / \mathrm{m}^{2}$ for pre-pregnancy BMI, which is lower than that identifying overweight $\left(25 \mathrm{~kg} / \mathrm{m}^{2}\right)$, the cutoff point largely used outside of pregnancy.

Waist circumference, although widely used in non-pregnant women to assess obesity and related health risks 14,15 , has received little attention in pregnancy. Sattar et al. 16 found that waist circumference was as good as BMI for predicting pregnancy-induced hypertension in women up to 16 weeks of gestational age. They suggested that a cutoff point of $80 \mathrm{~cm}$ could be used to define high risk, since it was related to an increased risk of developing preeclampsia $(\mathrm{OR}=2.7)$. We evaluated women between weeks 20 to 28, thus further along in pregnancy, and perhaps as a consequence, found that a slightly higher cutoff point $(82 \mathrm{~cm})$ had the best diagnostic properties. Additionally, we based our analyses of cutoff points for their diagnostic capacity to predict adverse outcomes, rather than to measure the strength of their associations with adverse outcomes.

Some limitations of our study merit discussion. Although we lost many patients to followup, the resulting bias is likely to be small, since those studied and those excluded were similar for the most important characteristics. In this regard, the exclusion of twin pregnancies may help explain the greater uterine height and waist circumference seen in the group without complete data. We have no reason to believe that those lost would have presented different diagnostic properties for the indices studied than those included. A limitation of our study is that pre-pregnancy BMI was calculated using reported prepregnancy weight, which is subject to recall error. However, since in many settings a measured pre-pregnancy weight is not available, our use of reported weight makes our results more applicable to routine clinical practice. Waist measurement is influenced by uterine volume in late pregnancy. This influence appears to become important when fundal height reaches $27 \mathrm{~cm} 17$, which corresponds, in our sample, to the median fundal height at 28 weeks of gestation. Since our objective was to find a good predictor of disease earlier, between 20 -28 weeks, a time when risk assessment for gestational diabetes is usually undertaken, we feel that our waist measurements were scarcely influenced and are applicable during this relevant clinical period of gestation. Further, when we stratified the analysis by fundal height above and below $27 \mathrm{~cm}$, we found similar results in each stratum.

One important advantage to this study is that we used a large population sample to evaluate the utility of three simple indicators of obesity as a screening method for obesity-related outcomes in pregnant women. This is illustrated by the reasonably small confidence intervals for the various diagnostic properties (Table 3 ).

Waist circumference is a good marker of fat distribution 18 , can be easily self measured 19 , and has been considered a better indicator of obesity-related health risks than BMI in the nonpregnant general population 20 . In our study, a waist circumference of $82 \mathrm{~cm}$ maximized sensitivity (63\%) and specificity (57\%) and as such, is potentially useful in predicting obesity-related outcomes (preeclampsia, gestational diabetes, and macrosomia) during pregnancy.

In conclusion, waist circumference, measured between 20 and 28 weeks of pregnancy, is a valid and simple method to identify pregnant women at higher risk of developing obesity-related adverse outcomes. Our data suggest that it performs as well as BMI indices in the prediction of these pregnancy complications. Waist circumference measured during the second trimester of pregnancy may be useful in prenatal nutritional evaluation and risk assessment. 


\section{Resumo}

O objetivo deste estudo é avaliar as propriedades diagnósticas da circunferência da cintura na predição de desfechos adversos da gestação relacionados à obesidade. Gestantes com 20 ou mais anos de idade, foram arroladas consecutivamente, entre 20 e 28 semanas de gestação, em seis capitais do Brasil, entre 1991 e 1995. Peso, altura e circunferência da cintura foram aferidos e um teste de tolerância à glicose foi realizado. As pacientes foram acompanhadas até o parto através de revisão de prontuários. Propriedades diagnósticas para os diferentes desfechos, mensurados através da área sob a curva Receiver Operator Charactheristic (ROC), foram estimadas por regressão logística. Áreas (IC95\%) sob as curvas ROC para a cintura foram 0,621 $(0,589-0,652)$ para diabetes gestacional, 0,640 (0,5880,692) para pré-eclâmpsia e 0,645 (0,617-0,673) para macrossomia. Estas áreas foram similares às encontradas para o IMC $(p>0,05)$. A cintura de $82 \mathrm{~cm}$ apresentou máximas sensibilidade (63\%) e especificidade (57\%). Um ponto de corte de $23 \mathrm{~kg} / \mathrm{m}^{2}$ para o IMC prégestacional e de $26 \mathrm{~kg} / \mathrm{m}^{2}$ para o IMC no arrolamento produziu propriedades diagnósticas semelhantes. A medida da circunferência da cintura prediz complicações como diabete gestacional, pré-eclâmpsia e macrossomia fetal tão bem quanto o IMC.

Obesidade; Gravidez; Antropometria

\section{Contributors}

M. I. Schmidt and B. B. Duncan coordinated the research. All the authors reviewed the initial drafts of the article and collaborated in the analysis.

\section{Acknowledgments}

We wish to acknowledge the participation of the following individuals in the development of this study: Brazilian Ministry of Health: Romero Bezerra Barbosa, Laurenice P. Lima, and Enrique Rivero Ortiz; Central Project Coordination: Maria Inês Schmidt, Angela J. Reichelt, Leandro Branchtein, Maria Cristina Gomes Matos, Sotero Mengue, Ivan Alejandro Relian, and Bruce B. Duncan; Quality Control Committee: Lúcia Iochida, Laércio J. Franco, and Ewaldo Russo; Porto Alegre Center: Angela J. Reichelt, Leandro Branchtein, and Maria Cristina Gomes Matos; Salvador Center: Judith Maria Dias Pousada, Maria Margarida dos Santos Britto, and Denise Barata; São Paulo Center: Tsuyoshi Yamashita and Cláudia Nogueira; Rio de Janeiro Center: Ethel R. Stambovsky Spichler and Cláudia Martins; Manaus Center: Margareth Mauro Teixeira and Maria Cristina Tavares da Costa; Fortaleza Center: Adriana Costa e Forti and Eni Fleck de Paula Pessoa.

\section{References}

1. World Health Organization. Obesity: preventing and managing the global epidemic. Report of a WHO consultation. Geneva: World Health Organization; 2000. (WHO Technical Report, 894).

2. Johnson JW, Longmate JA, Frentzen B. Excessive maternal weight and pregnancy outcome. Am J Obstet Gynecol 1992; 167:353-70.

3. Cnattingius S, Bergstrom R, Lipworth L, Kramer MS. Pre-pregnancy weight and the risk of adverse pregnancy outcomes. N Engl J Med 1998; 338: 147-52.

4. World Health Organization. Physical status: the use and interpretation of anthropometry. Geneva: World Health Organization; 1995.

5. Nucci LB, Schmidt MI, Duncan BB, Fuchs SC, Fleck ET, Santos Britto MM. Nutritional status of pregnant women: prevalence and associated pregnancy outcomes. Rev Saúde Pública 2001; 35:502-7.

6. NHLBI Obesity Education Initiative. Clinical guidelines on the identification, evaluation and treatment of overweight and obesity in adults: the evidence report. The Evidence Report. Bethesda: National Heart, Lung and Blood Institute, National Institute of Health; 1998. (No. 98-4083).
7. World Health Organization. Prevention of diabetes mellitus. Report of a WHO Study Group. Geneva: World Health Organization; 1994. (WHO Technical Report, 844).

8. Schmidt MI, Duncan BB, Reichelt AJ, Branchtein L, Matos MC, Costa-e-Forti A, et al. Gestational diabetes mellitus diagnosed with a 2-h 75-g oral glucose tolerance test and adverse pregnancy outcomes. Diabetes Care 2001; 24:1151-5.

9. Hanley JA, McNeil BJ. A method of comparing the areas under receiver operating characteristic curves derived from the same cases. Radiology 1983; 148:839-43.

10. Thadhani R, Stampfer MJ, Hunter DJ, Manson JE, Solomon CG, Curhan GC. High body mass index and hypercholesterolemia: risk of hypertensive disorders of pregnancy. Obstet Gynecol 1999; 94:543-50.

11. Baeten JM, Bukusi EA, Lambe M. Pregnancy complications and outcomes among overweight and obese nulliparous women. Am J Public Health 2001; 91:436-40.

12. O'Brien TE, Ray JG, Chan WS. Maternal body mass index and the risk of preeclampsia: a systematic overview. Epidemiology 2003; 14:368-74. 
13. Lu GC, Rouse DJ, DuBard M, Cliver S, Kimberlin D, Hauth JC. The effect of the increasing prevalence of maternal obesity on perinatal morbidity. Am J Obstet Gynecol 2001; 185:845-9.

14. Zhu S, Wang Z, Heshka S, Heo M, Faith MS, Heymsfield SB. Waist circumference and obesity-associated risk factors among whites in the third National Health and Nutrition Examination Survey: clinical action thresholds. Am J Clin Nutr 2002; 76:743-9.

15. Foucan L, Hanley J, Deloumeaux J, Suissa S. Body mass index (BMI) and waist circumference (WC) as screening tools for cardiovascular risk factors in Guadeloupean women. J Clin Epidemiol 2002; 55:990-6.

16. Sattar N, Clark P, Holmes A, Lean ME, Walker I, Greer IA. Antenatal waist circumference and hypertension risk. Obstet Gynecol 2001; 97:268-71.
17. Branchtein L, Schmidt MI, Mengue SS, Reichelt AJ, Matos MC, Duncan BB. Waist circumference and waist-to-hip ratio are related to gestational glucose tolerance. Diabetes Care 1997; 20:509-11.

18. Ross R, Leger L, Morris D, de Guise J, Guardo R. Quantification of adipose tissue by MRI: relationship with anthropometric variables. J Appl Physiol 1992; 72:787-95.

19. Rimm EB, Stampfer MJ, Colditz GA, Chute CG, Litin LB, Willett WC. Validity of self-reported waist and hip circumferences in men and women. Epidemiology 1990; 1:466-73.

20. Janssen I, Katzmarzyk PT, Ross R. Waist circumference and not body mass index explains obesity-related health risk. Am J Clin Nutr 2004; 79:379-84.

Submitted on 24/May/2005

Final version resubmitted on 10/Jan/2006 Approved on 02/Feb/2006 